\title{
Investigation of radio waves propagation models in Nigerian rural and sub-urban areas
}

\author{
Shoewu, $O$ and Adedipe, A. \\ Department of Electronic and Computer Engineering, Lagos State University, Epe Campus \\ ABSTRACT
}

\begin{abstract}
Various propagation models have been described by various research experiments in recent times. The results of each experiment depend largely on the environmental conditions under which each experiment was carried out. This model can be applied under similar environmental conditions. This research attempts to investigate the effectiveness of the Okumura-Hata model in a typical Nigerian terrain. A GSM base station operation at $900 \mathrm{MHz}$ band was used for the experiment in a typical sub-urban area within the Northern part of Nigeria. The field measurement results were compared with Okumura-Hata model for rural and sub-urban area. The results obtained indicate the least variation with Okumura-Hata model for sub-urban areas.
\end{abstract}

Keywords: Radio waves, propagation, Nigeria

\section{INTRODUCTION}

A very crucial factor in mobile cellular network projects is the ability to make an accurate prediction of propagation path loss within an environment. An accurate prediction model will assist tremendously in the planning, design and even implementation processes of a mobile cellular network project.

It is important to note that these models are formulated as a result of the geographic and environmental factors within the environment where the study is being performed. This project is aimed at investigating the effectiveness of commonly used Okumura-Hata model, which is used for macro-cells within rural and suburban areas, in northern part of Nigeria.

The investigated environment: The location for this experiment was carefully selected as much as possible to emulate that which the Okumura-Hata experiment was performed. A base station operating at $900 \mathrm{MHZ}$ frequency bands was used for the experiment to achieve more accurate experimental results.

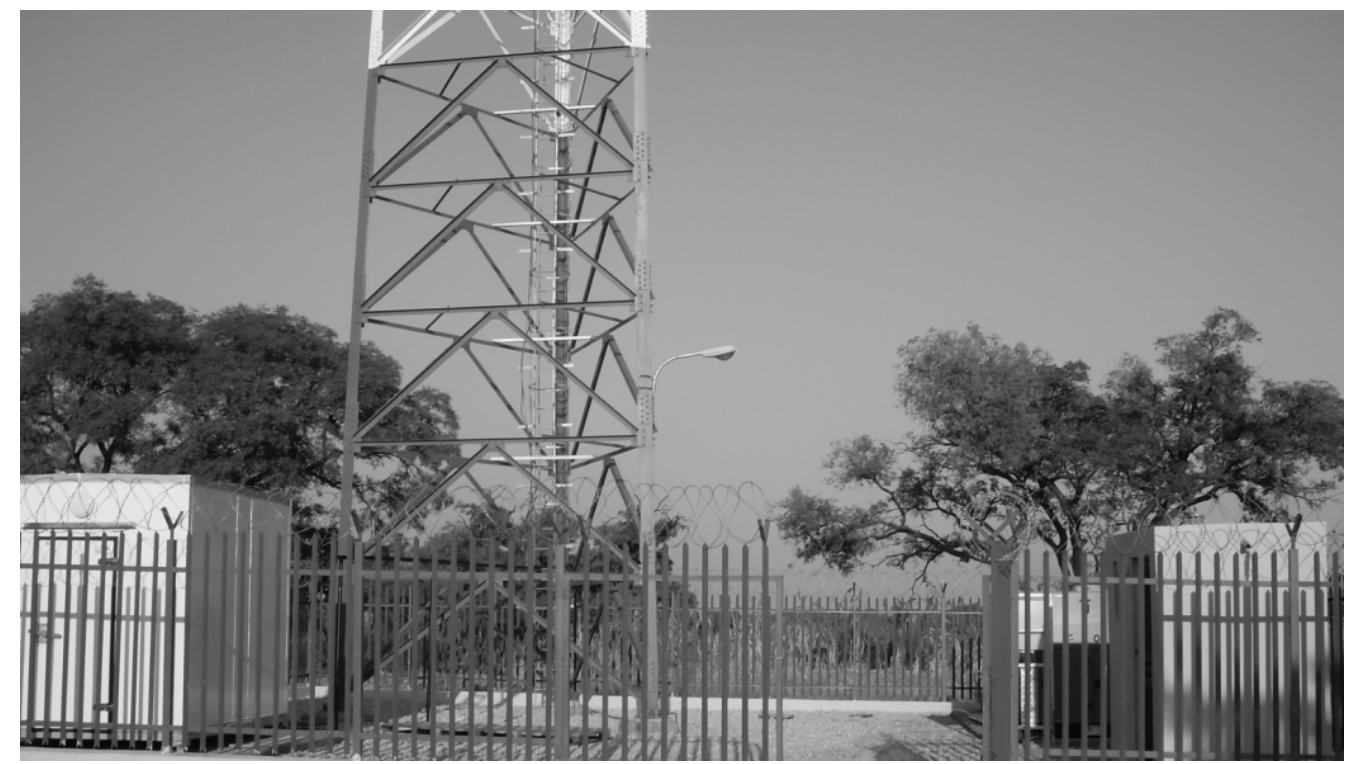

Fig 1: Image of the site used. 
Literature review of propagation models: Various propagation models have been developed over the decades to estimate the propagation path loss at various receiver distances from a transmitting base station. These models include the free space model, Okumura-Hata model, Walfish-lkegani model, Keenan-Motley model and Cost-231 model. Once the propagation path loss can be predicted with a level of accuracy, then the received signal power distribution $\left(P_{r}\right)$ at the respective distances can be easily obtained with the expression:

The effective power radiated from the BTS antenna $\left(P_{t \text { in dBm }}\right)$ is given as:

$$
P_{t}=P_{B T S}-P_{C}-P_{f}+\left(A_{m s}+A_{B T S}\right)
$$

Where

$$
\begin{array}{cccc}
\mathrm{P}_{\mathrm{BTS}} & = & \text { base station power } \\
\mathrm{P}_{\mathrm{D}} & = & \text { duplexer loss } \\
\mathrm{P}_{\mathrm{f}} & = & \text { feeder loss } \\
\mathrm{A}_{\mathrm{ms}} & = & \text { Mobile } & \text { station } \\
\text { (receiver) antenna gain } & & \\
\mathrm{A}_{\mathrm{T}} & = & \text { the base station }
\end{array}
$$

antenna gain

The effective radiated power is subject to propagation loss $\left(P_{L}\right)$ along its path due to reflection, diffraction, retraction, scattering, etc. Power at the receiver distances from the base station is expressed as:

$$
\begin{aligned}
& P_{L}=P_{t}-P_{r} \quad \text { (in dBm) } \\
& P_{L}(d B)=10 \log _{10}\left(P_{t} / P_{r}\right)
\end{aligned}
$$

The various models as will be shown below performed their experiments to obtain their respective path loss models under specific conditions.

Free space model: The free space model assumes an ideal situation where there are no obstacles that could cause reflection, diffraction or scattering within the line-of-sight between the transmitter and receiving stations. Thus the attenuation of the radio wave signal is proportional to the distance from the transmitter. The receiver power density, at a distance $\mathrm{d}$ from the transmitter, is expressed as:

$$
\begin{aligned}
& D=\frac{P_{t} A_{t}}{4 \pi d^{2}} \quad \text { where } A_{t}-\text { BTS Transmitter } \\
& \text { antenna gain }
\end{aligned}
$$

Effective area of the receiver antenna is

$$
A=\frac{\lambda^{2} A_{r}}{4 \pi}
$$

The receiver power density can also be written as

$$
\begin{aligned}
D= & \frac{P_{r}}{A} \\
& \mathrm{P}_{\mathrm{r}}=\mathrm{P}_{\mathrm{t}} \mathrm{A}_{\mathrm{t}} \mathrm{A}_{\mathrm{r}}(\lambda / 4 \mathrm{~d})
\end{aligned}
$$

Path loss

$$
P_{L}=10 \log \left(P_{t} / P_{r}\right)
$$

Since $f$ is in $\mathrm{MHZ}\left(10^{6}\right)$ and $\mathrm{d}$ is $\mathrm{km}\left(10^{3}\right)$;

$$
P_{L}=32.44+20 \log (f)+20 \log (d)
$$

Practically, the ideal situation upon which this model was derived is not realistic. Radio wave signal power attenuation depends largely on the frequency band and terrain types between the transmitting and receiving antenna. The propagation path loss varies according to the terrain type and this should be given serious consideration in propagation path loss modeling. This is done using the correction factor for each terrain. A more realistic path loss model is the Okumura-Hata model for macrocells in rural and suburban areas.

Okumura-hata model: One of the most common propagation model for predicting signal attenuation in a macro cell environment is the Okumura-Hata model. It is important to note here that although estimation is easier in this model, but it is limited to frequency of $150-1500 \mathrm{MHZ}$, receiver distance of 1$20 \mathrm{~km}$, transmitter antenna height of $3-200 \mathrm{~m}$ and receiver antenna height of $1-10 \mathrm{~m}$.

The Okumura-Hata model is expressed as:

$$
\begin{gathered}
P_{1}=x+y \log (f)-13.82 \log \left(h_{t}\right)-C r+ \\
\left(44.9-6.55 \log \left(h_{t}\right)\right) \log (d)+c_{0}
\end{gathered}
$$

Where $x$ and $y$ are frequency dependent parameters and are given as 69.55 and 26.16 respectively within the frequency range.

$h_{t}=$ transmitter antenna height in meters, $\mathrm{h}_{\mathrm{r}}=$ receiver antenna height in meters

$\mathrm{C}_{\mathrm{r}=}$ receiver correction factor, $\mathrm{C}_{0}$ =additional correction factor depending on the terrain type

$\mathrm{C}_{\mathrm{r}}=[1.1 \log 10(\mathrm{f})-0.7) \mathrm{h}_{\mathrm{r}}-(1.56 \log 10(\mathrm{f})-0.8]$

Project methodology: This project involves obtaining the mean receive power distribution at specified receiver distances from a two sector GSM base station in the rural area of Sabon Rijiya along Bauchi-Potiskum Road, Bauchi State. The path loss value was then obtained.

The obtained values from field measurements are then compared with those calculated using the 
existing models. The essence of this is to investigate the degree of consistency of these existing models with field measurements.

Experimental setup and data collection: A site verification exercise was done using Ericsson k800i mobile station \& a piece of compass. This is to ensure that the BTS sites used were performing optimally and meets up with all parameters as stated:

BTS power: $40 \mathrm{~W}$, BTS antenna ht: $55 \mathrm{~m}$, MS Antenna ht: $1.2 \mathrm{~m}$,

Transmitter antenna ht: 55m, Frequency band: $900 \mathrm{MHZ}$,
Connector loss: 3dB, Feeder loss: $2.58 \mathrm{~dB}$, Duplexer loss: $4.5 \mathrm{~dB}$

Data collection was performed thereafter using a test kit consisting of the following:

Ericsson TEMS investigation software 8.0.3 version

Sony Ericsson k800i mobile station with TEMS software.

Garmin GPS 76 with 0db loss antenna.

Personal computer with the TEMS software.

Radio works 2.0 software.

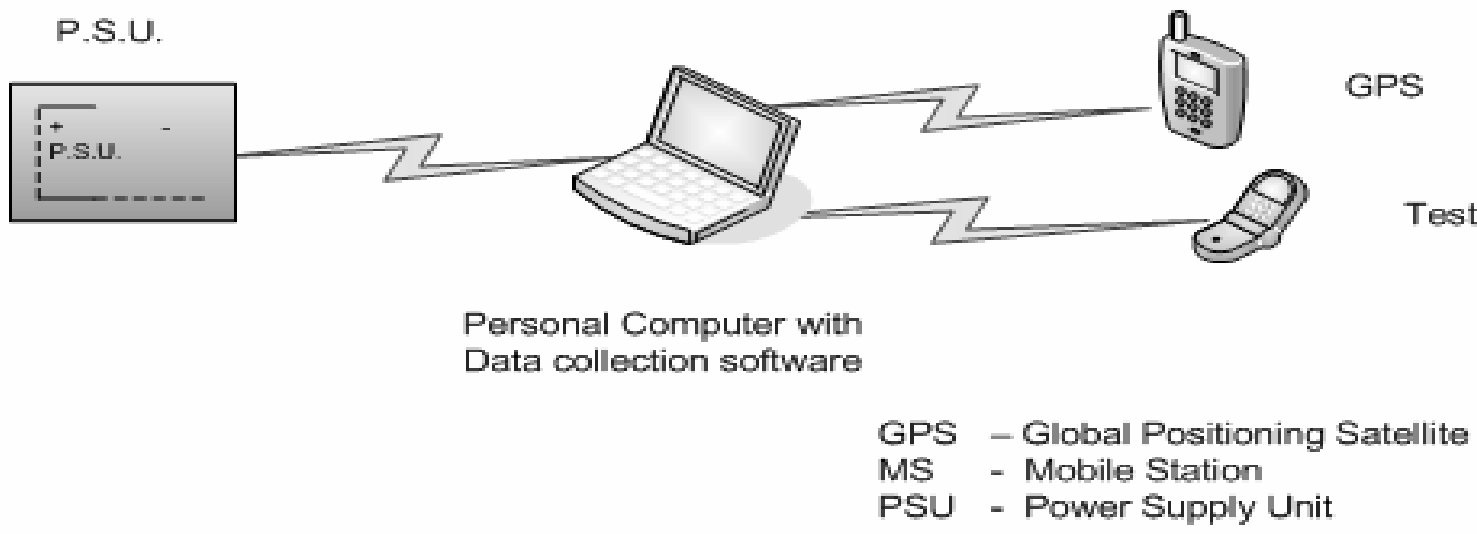

Fig 2: Experimental Setup

With the equipment above in a vehicle maintained at an average speed of $30 \mathrm{~km} / \mathrm{h}$, data collection was done starting from a distance of less than $100 \mathrm{~m}$ from the base station. The vehicle then moves along the direction of the main lobes of each directional antenna away from the site until it gets to the coverage border. This process was repeated for both sectors of the site under which the experiment was performed. Below is the pictorial representation of the drive test data as captured from the data collection software interface. 


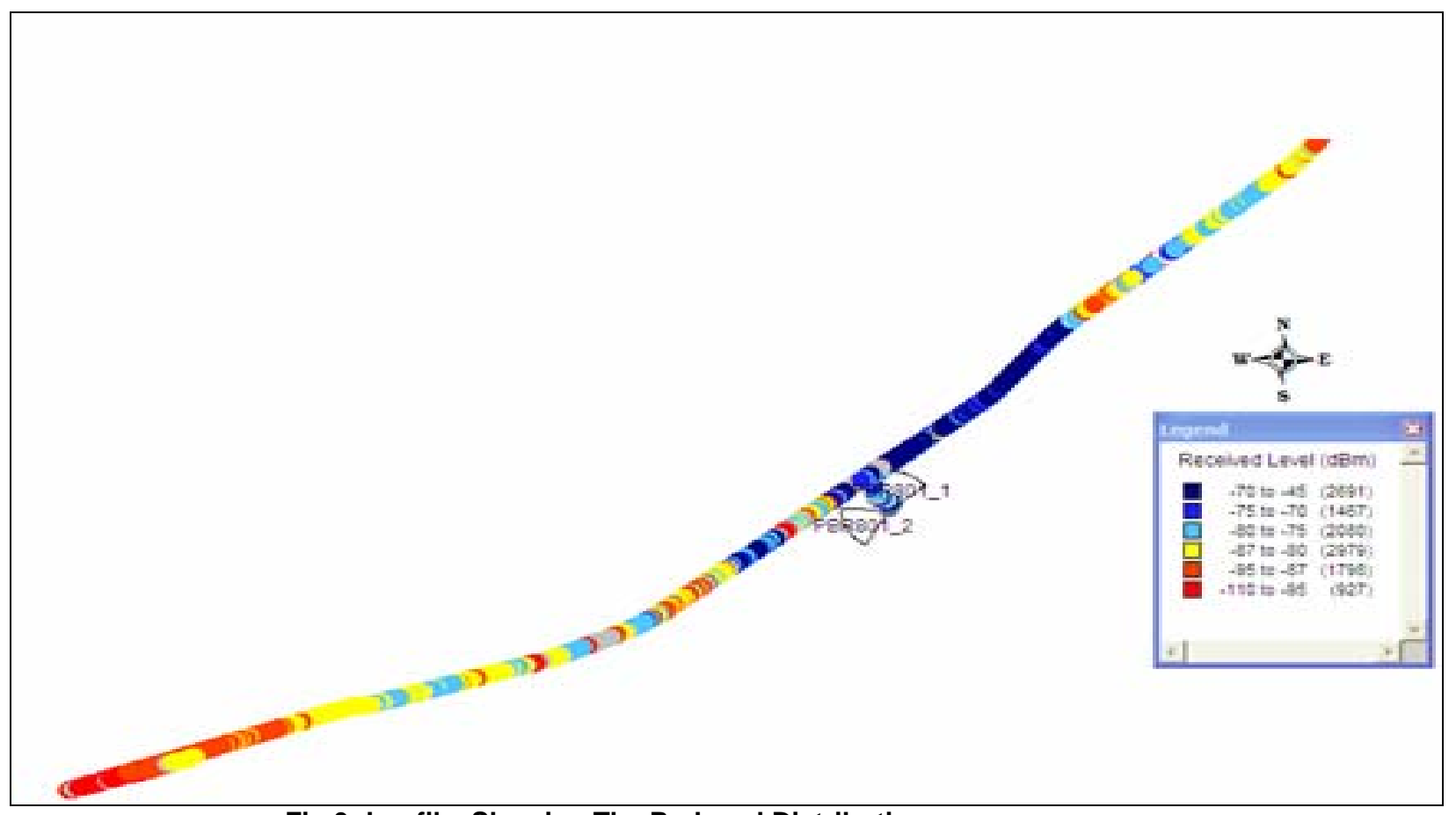

Fig 3: Logfile Showing The Rx-Level Distribution

From the above interface, the receive power $P_{r}$ was then obtained at the different specified receiver distances.
Data analysis and results: From the data obtained above, the received power level at various receiver distances from each sectors of the BTS site is as tabulated below:

\section{Field measurement results:}

Table 1: Mean Receive Level Distribution

\begin{tabular}{|l|l|l|l|l|}
\hline & \multicolumn{2}{l|}{ Rx-Power (dBm) } & \\
Distances(km) & Sector A & Sector B & Mean Rx-Power & Path loss(dBm) \\
\hline 0.5 & -58.0 & -58.0 & -58.0 & 114.9 \\
\hline 1.0 & -61.0 & -60.0 & -60.5 & 118.4 \\
\hline 1.5 & -63.0 & -63.0 & -63.0 & 119.9 \\
\hline 2.0 & -65.0 & -66.0 & -65.5 & 122.4 \\
\hline 2.5 & -68.0 & -68.0 & -68.0 & 124.9 \\
\hline 3.0 & -71.0 & -73.0 & -72.0 & 128.9 \\
\hline 3.5 & -75.0 & -76.0 & -75.5 & 132.4 \\
\hline 4.0 & -78.0 & -79.0 & -78.5 & 135.4 \\
\hline 4.5 & -80.0 & -82.0 & -81.0 & 137.9 \\
\hline 5.0 & -89.0 & 91.0 & -89.5 & 146.4 \\
\hline 6.0 & -92.0 & -96.0 & -94.0 & 150.9 \\
\hline 8.0 & -103.0 & -101.0 & -102.0 & 158.9 \\
\hline 10.0 & -115.0 & -118.0 & -116.5 & 173.4 \\
\hline
\end{tabular}


Am. J. Sci. Ind. Res., 2010, 1(2): 227-232

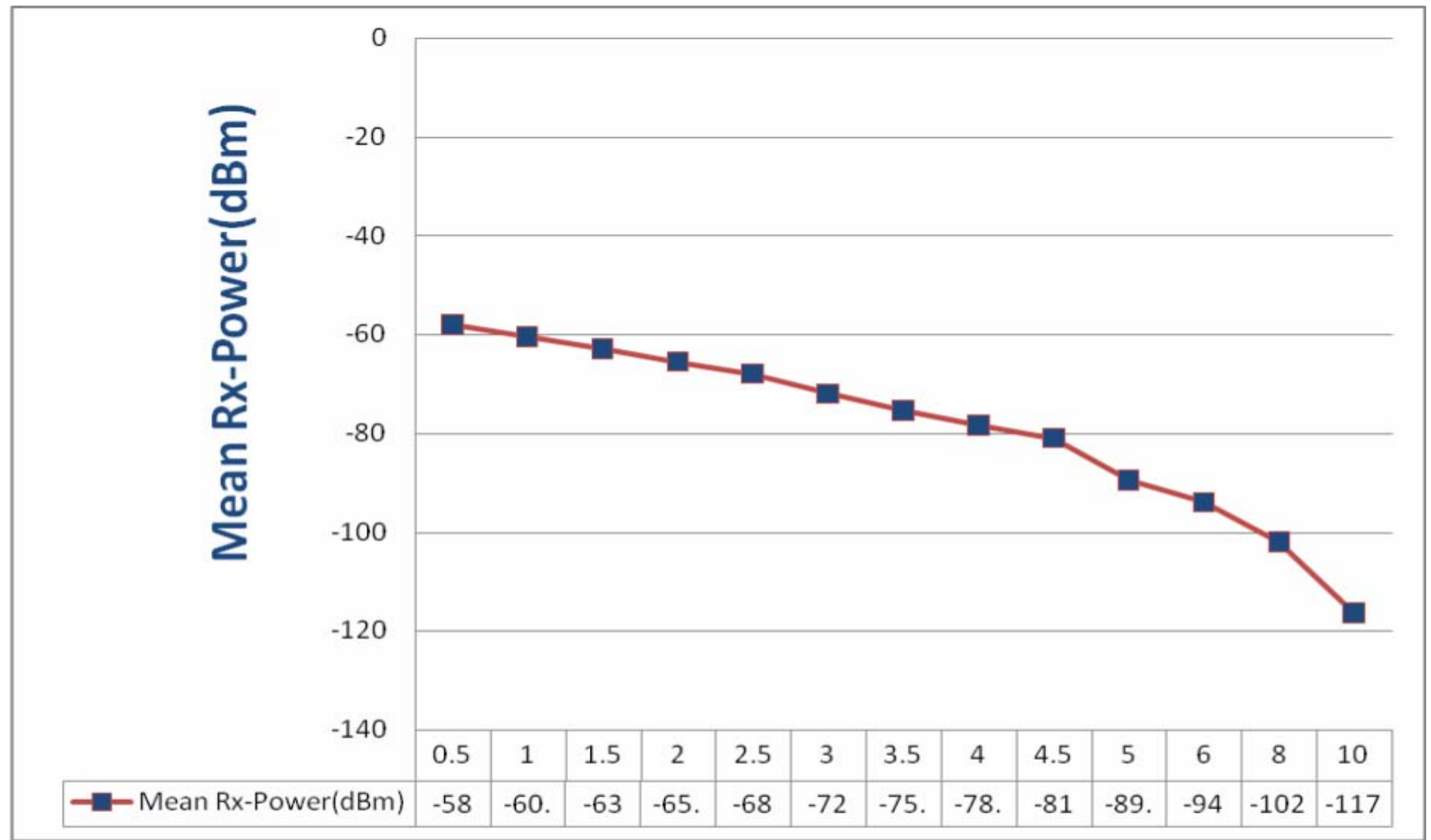

Fig 4: Mean Rx-Power Vs Distance Graph

It can be seen from Table 1 that the mean Receive power diminishes with increase in receiver distance. A good reception is obtained at distances above $5 \mathrm{~km}$ from the base station. From the Receive obtained, the corresponding pathloss $(\mathrm{dBm})$ was obtained using the expression $P_{L}=10 \log \left(P_{t} / P_{r}\right)$.

Figure 3 shows the Receive power distribution at different receiver distances from the transmitting station.

\section{FIELD MEASUREMENTS}

\section{PATHLOSS DISTRIBUTION TABLE}

Table 2: Path Loss Distribution

\begin{tabular}{|l|l|l|l|l|}
\hline $\begin{array}{c}\text { Distances } \\
(\mathbf{k m})\end{array}$ & $\begin{array}{l}\text { Free space } \\
\text { model(dBm) }\end{array}$ & $\begin{array}{l}\text { Okumura-Hata model } \\
\text { Suburban(dBm) }\end{array}$ & $\begin{array}{l}\text { Okumura-Hata model Rural } \\
(\mathbf{d B m})\end{array}$ & $\begin{array}{l}\text { Test } \\
(\mathbf{d B m})\end{array}$ \\
\hline 0.5 & 85.5 & 104.01 & 85.42 & 114.9 \\
\hline 1.0 & 91.52 & 114.1 & 95.5 & 118.4 \\
\hline 1.5 & 95.05 & 120 & 101.4 & 119.9 \\
\hline 2.0 & 97.55 & 124.18 & 105.59 & 122.4 \\
\hline 2.5 & 99.48 & 127.43 & 108.83 & 124.9 \\
\hline 3.0 & 101.07 & 130.08 & 111.49 & 128.9 \\
\hline 3.5 & 102.41 & 132.32 & 113.73 & 132.4 \\
\hline 4.0 & 103.57 & 134.27 & 115.67 & 135.4 \\
\hline 4.5 & 104.59 & 135.98 & 117.39 & 137.9 \\
\hline 5.0 & 105.5 & 137.51 & 118.92 & 146.4 \\
\hline 6.0 & 107.09 & 139.66 & 121.06 & 150.9 \\
\hline 8.0 & 109.59 & 143.84 & 125.25 & 173.9 \\
\hline 10.0 & 111.52 & 147.09 & 128.49 & 173.4 \\
\hline
\end{tabular}


Am. J. Sci. Ind. Res., 2010, 1(2): 227-232

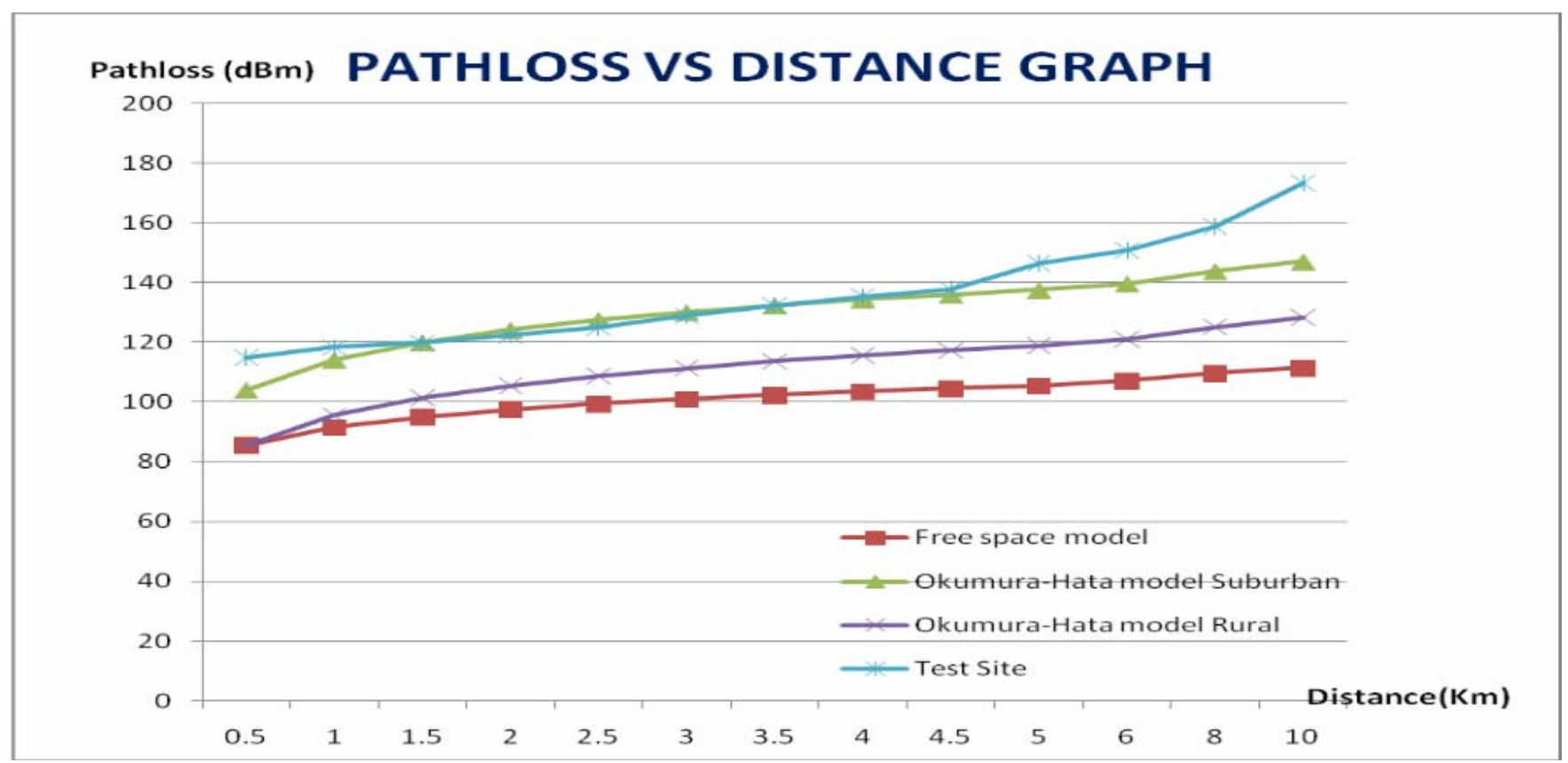

Fig 5: Pathloss Vs Distance Graph

Conclusion and discussion: The pathloss distribution graph in Figure 4 shows the relationship that exists among the various propagation models in terms of pathloss. It can be seen that there are variations between field measurement results and the existing models. An exception is that of OkumuraModel for sub-urban areas in which only a slight variation exists for distances up to $5 \mathrm{~km}$. For rural areas, there is an appreciable deviation from the measured results.

This research thus shows that the Okumura-Hata model for radio wave propagation is very effective for radio wave propagation pathloss prediction in suburban areas in Northern part of Nigeria.

\section{REFERENCES}

1. Arne Schmitz and Martin Wenig (2008) "The Effect of the Radio Wave Propagation Model in Mobile Ad Hoc Networks" Proceedings Of World Academy Of Science, Engineering And Technology Volume 36 December 2008 ISSN 2070-3740

2. T.L. Adebayo and F.O. Edeko (2006) "Characterisation of Propagation Path Loss at 1.8GHz:A Case study of Benin city, Nigeria." Research Journal of Applied Sciences: Medwell online 2006.

3. Ajay Mishra (2007) "Advance Cellular Network Planning and Optimisation "John Wiley and Sons 2007. 